\title{
Carotid Artery Mobilization to Increase the Working Zone Area in Optic Carotid Triangle and Carotid Oculomotor Triangle (A Technical Note of Proximal and Distal Dural Ring Release)
}

\author{
Iype Cherian ${ }^{1}$, Mohammed Alaswad $^{2}$, Edmundo Valencia Bayona ${ }^{3 *}$, Andrea Gerosa ${ }^{4}$, Manuel \\ López $^{5}$ and Aldo Spallone ${ }^{6}$ \\ ${ }^{1}$ Nobel Institute of Neurosciences, Nobel Teaching Hospital, Biratnagar, Nepal \\ ${ }^{2}$ Suez Canal University, El Ismalia, Egypt \\ ${ }^{3}$ Russian University "Druzhby Narodov", Russia \\ ${ }^{4}$ University of Pavia, Italy \\ ${ }^{5}$ General Mexico Hospital, "National Autonomous University of Mexico", Mexico \\ ${ }^{6}$ Neuromed-Ncl, Institute of Neurological Sciences, Italy \\ *Corresponding author: Edmundo Valencia Bayona, Russian University “Druzhby Narodov", Russia
}

\section{ARTICLE INFO}

Received: 幽 September 09, 2020

Published: 慧 November 06, 2020

Citation: Iype Cherian, Mohammed Alaswad, Edmundo Valencia Bayona, Andrea Gerosa, Manuel López, Aldo Spallone. Carotid Artery Mobilization to Increase the Working Zone Area in Optic Carotid Triangle and Carotid Oculomotor Triangle (A Technical Note of Proximal and Distal Dural Ring Release). Biomed J Sci \& Tech Res 31(4)-2020. BJSTR. MS.ID.005148.

\section{ABSTRACT}

Background: The internal carotid artery (ICA) is attached to the anterior clinoid process and to the dural rings. Mobilization of the ICA in order to work on in the opticocarotid and carotid oculomotor triangle without dural ring release is a demanding procedure.

Methods: In this paper we describe the technique of dural rings release, which is adopted by the senior author.

Results: Intraoperative pictures of various sellar and parasellar lesions are shown with adequate view of the paraclinoid spaces.

Conclusion: Dural ring release is crucial for widening the working paraclinoid triangles especially in cases of short supra-clinoidal portion of ICA.

Keywords: Clinoidal Space, Paraclinoidal Aneurysms, Basilar Tip Aneurysms, SellarParasellar Lesions

Abbreviations: ACP: Anterior Clinoid Process; MOB: Meningo-Orbital Band; SOF: Superior Orbital Fissure; COM: Carotid-Oculomotor Membrane

\section{Short Communication}

Optic carotid and carotid oculomotor triangles are the main corridors for reaching sellar and parasellar lesions as well as basilar apex and paraclinoidal aneurysms. The ICA is fixed to the anterior clinoid process and to the dural rings [1]. Thus, its mobility is restricted, and surgery performed through these triangles is demanding. This will be evident especially in cases of short supraclinoidal portion of ICA [2]. Several anatomic morphometric studies showed the effect of anterior clinoidectomy on improving the working area in both triangles [3-5]. However, the surgical technique of paraclinoidal carotid artery mobilization via dural rings release is not clearly described in the literature. In fact, the additional space created by anterior clinoidectomy alone is not sufficient to mobilize the paraclinoidal portion of ICA. We here illustrate the technique of releasing both rings for mobilizing ICA. 


\section{Dural Rings Anatomic Review}

The lateral wall of cavernous sinus consists of 2 layers, dura propria and a thin layer called the membranous layer. These two dural layers separate the cavernous extradural ICA from its subdural portion. At the lateral border of the anterior clinoid process (ACP) these dural layers split to cover its upper and lower surfaces. The layer, which covers the upper and lateral surface, forms the distal dural ring and continues medially to the diaphragma sellae to become falciform ligament. On the other hand, the layer which covers the lower and medial surfaces of the ACP is called proximal dural ring, this surrounds the ICA in a loose manner in contrast to the distal dural ring which is firmly adhered [6].

\section{Surgical Technique Philosophy}

The philosophy of this technique is based on the creation of a wide clinoidal space. This is the area occupied by ACP, set free by clinoidectomy itself. This space is bounded superiorly by distal dural ring and inferiorly by the proximal dural ring and constitutes the working channel for dural rings release.

\section{Surgical Technique}

\section{Step 1: Identification of Meningo-Orbital Band after Frontotemporal Craniotomy}

The Meningo-orbital band (MOB) is a constant landmark along the most lateral part of the superior orbital fissure (SOF). Finding of the MOB indicates optimal bone drilling. Optimal drilling indicates flattening of the temporal bone to reach the level of middle fossa dura plus drilling of the lesser wing of sphenoid to reach the level of SOF. MOB tethers the fronto-temporal dura to the periorbita, thus it limits adequate extradural exposure of the ACP. It contains an artery carrying its name and no cranial nerves. Good and adequate extradural dissection of basal frontal and temporal dura will reveal the area of MOB (Figure 1).
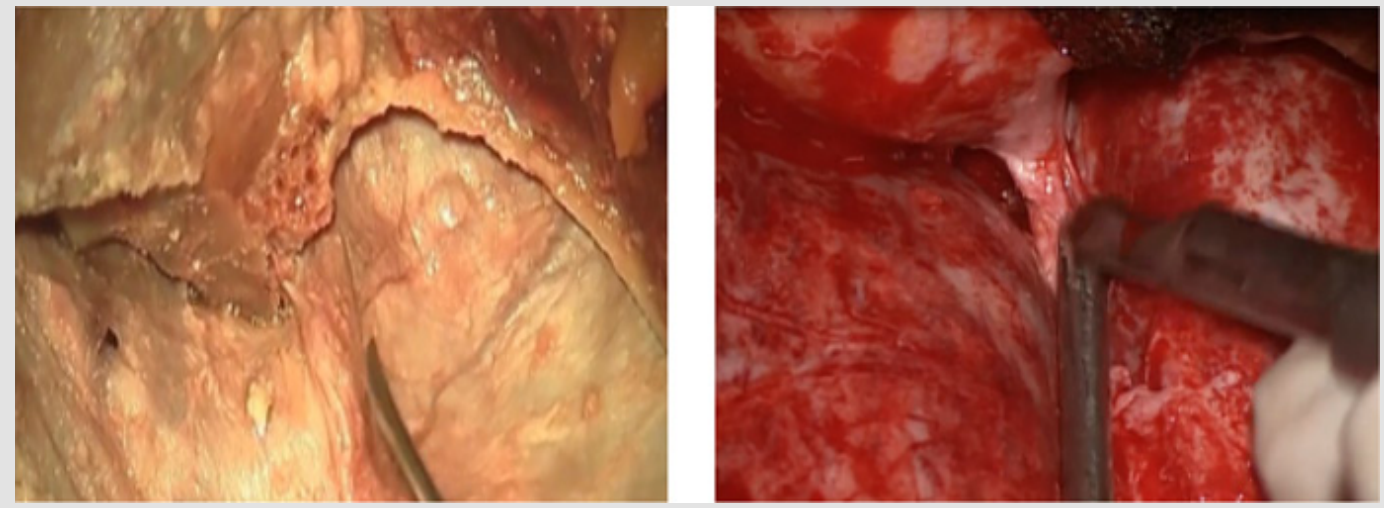

Figure 1: MOB in a cadaveric specimen and from a live case. Note the attachment of MOB to the periorbita in the right image. It is better demonstrated in modified orbito-zygomatic craniotomy).

\section{Step 2: Cutting the MOB to Create a Plane between the Dural Layers of the Lateral Wall of Cavernous Sinus}
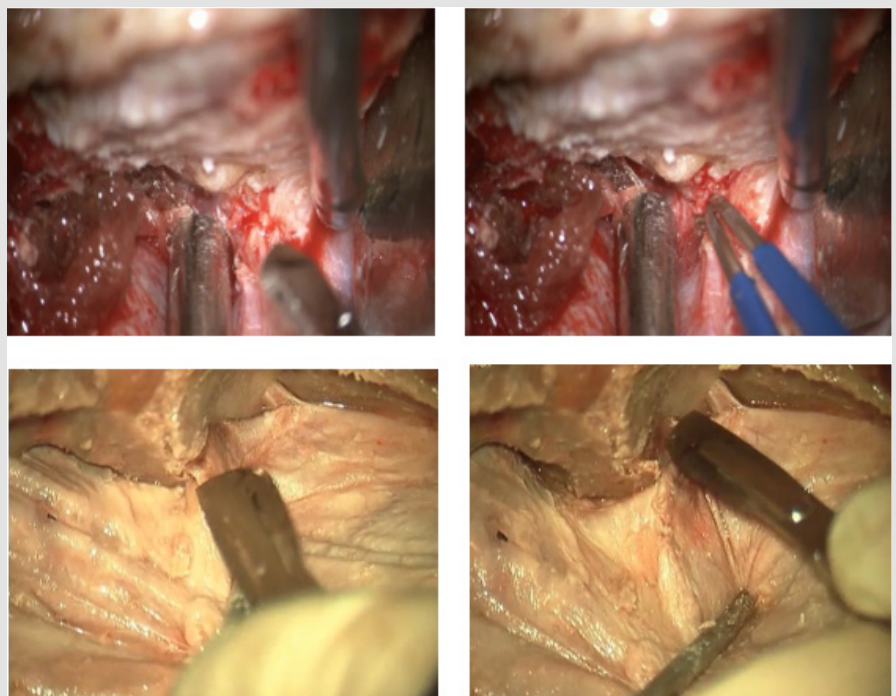

Figure 2: The upper row showing how to coagulate and cut the MOB. The lower row images illustrating the same technique in cadaveric specimen. 
Developing a plane between the true dural layer and the inner layer using microscopic high magnification and sharp dissection is the key to expose the lateral wall of cavernous sinus by uncovering the infero-lateral part of ACP. Coagulating the MOB and its vessels should not exceed a distance of 3 to $5 \mathrm{~mm}$. in order to avoid unintentional damage to the cranial nerves running towards the cavernous sinus. The cleavage plan should be established first at the temporal tip in the lateral wall of cavernous sinus. This would achieve bloodless dissection and early identification of the lateral and inferior aspects of ACP. Dissection could be extended laterally if needed to expose the $3^{\text {rd }}$ división of trigeminal nerve and the tentorial edge medially as well. This dissection is also of paramount importance to identify the optic nerve intradurally (Figures $2 \& 3$ ).
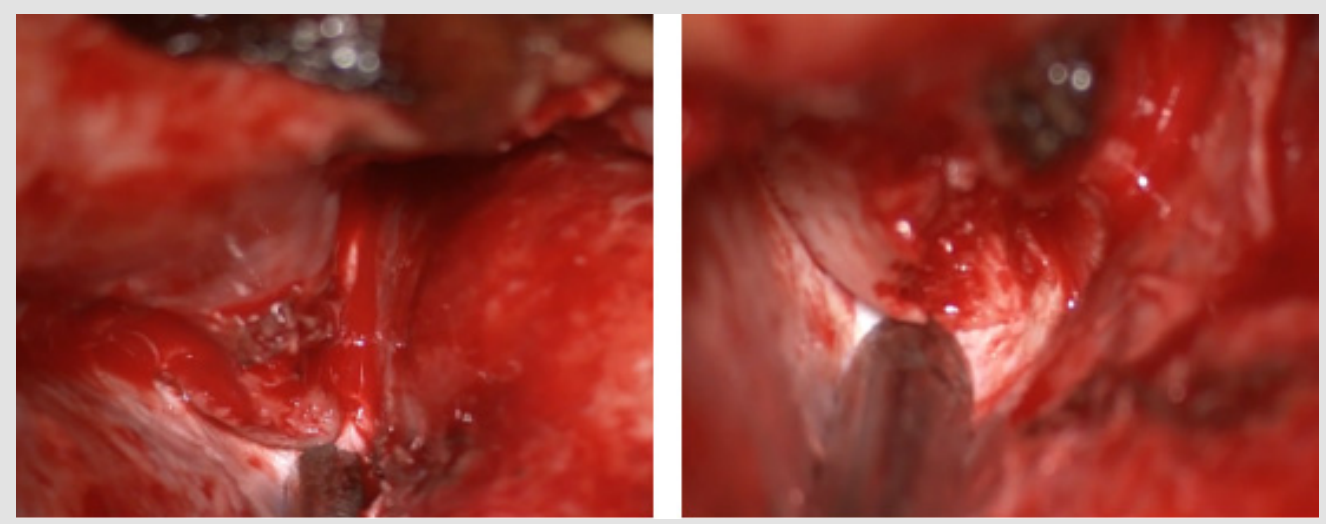

Figure 3: The left image showing the stump of $\mathrm{MOB}$ after coagulation and cutting. The right image exhibits the final product of $\mathrm{MOB}$ cutting (ACP at the tip of suction tube).

\section{Step 3: Extradural Anterior Clinoidectomy}

Anteriorly, the base of the ACP has one lateral and two medial components: Laterally, it is the continuation of the lesser wing of the sphenoid bone overlying the SOF; medially, the base connects to the sphenoid bone via the anterior and posterior roots. The anterior root, located superiorly, is the continuation of the flat roof of the optic canal. The posterior root, located inferomedially, is the optic strut and connects the ACP to the sphenoid bone. Usually clinoidectomy is accomplished via three steps. Firstly, osteotomy along the medial aspect of the sphenoid bone detaches the lateral connection of ACP. Identification of the upper portion of the SOF is the confirmation of the completion of this step. Secondly, before the clinoid process is manipulated, the dorsal and lateral walls of the optic canal which forms the anterolateral root of ACP are unroofed using a small diamond drill from lateral to medial direction under continuous irrigation to avoid heat injury to the nerve.
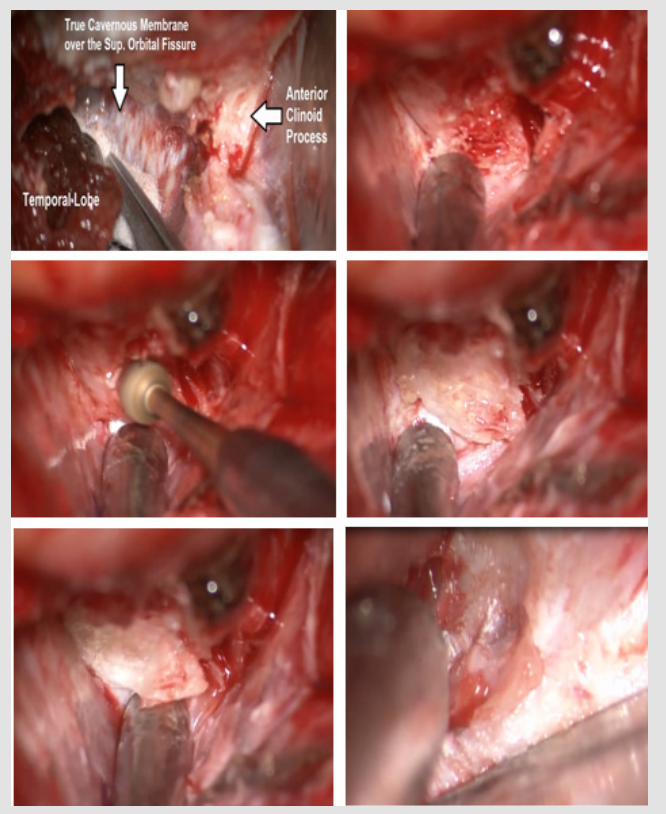

Figure 4: The anatomic landmarks after MOB cutting and dissection of lateral cavernous wall and SOF dura (upper left image). In the next images the stepwise technique of extradural clinoidectomy until the identification of carotid and optic nerve extradurally (right lower image in last row). 
The cortical bone over the nerve is "egg-shelled" and a fine curette is used to remove this thin layer of bone, care is taken not to open either the ethmoid or sphenoid sinus at the medial edge of the optic canal. If the sinuses are entered, we do not violate the mucous membrane and close the bone opening with wax. Finally, with a clear view of the optic nerve, the diamond burr is used to core out the central cancellous bone and "egg-shell" the remaining cortical bone of the clinoid process. This maneuver disconnects the final attachment of the process to the optic strut. The third cranial nerve should be protected during anterolateral drilling. The final view will be a complete visualization of extra dural C3 carotid artery and optic nerve (Figure 4).

\section{Step 4: Intradural Identification of Carotid Artery and Optic Nerve}

After standard dural incision and distal Sylvian fissure dissections, the optic nerve is identified medial to the ICA and the oculomotor nerve is identified on the lateral side. Opening all basal cisterns will slack the brain further (Figure 5).
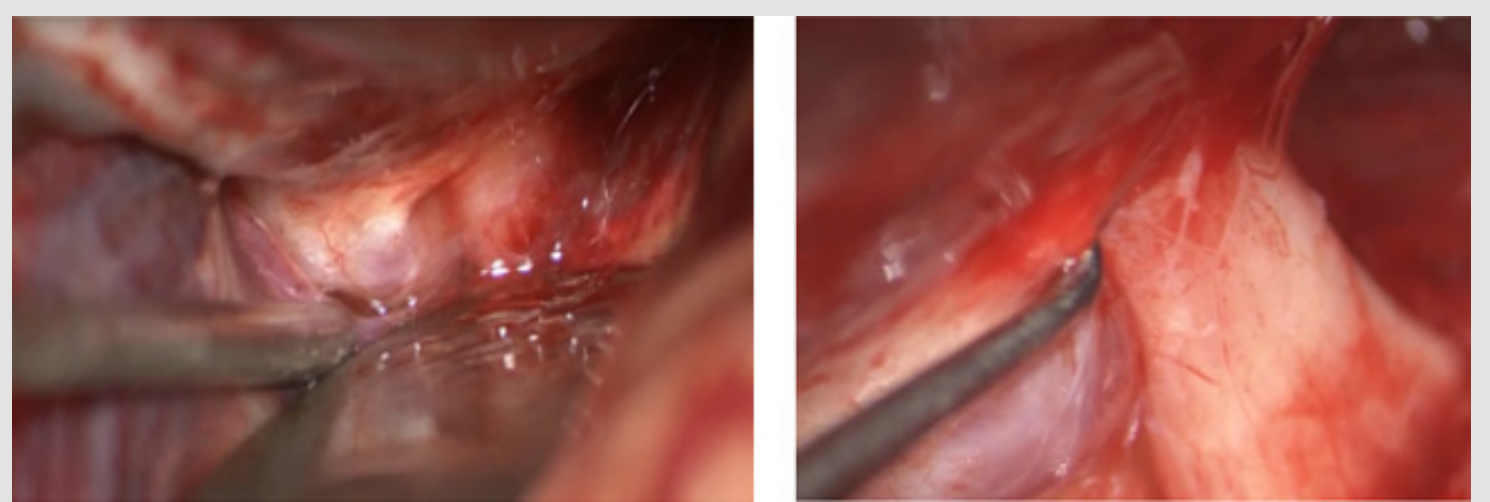

Figure 5: Intradural exposure of optic nerve and ICA before arachnoid dissection (left image) and after arachnoid dissection (right image).

Step 5: Intra Dural Cutting of the Falciform Ligament and

\section{Optic Nerve Sheath}

Under high magnification by using blunt hook, the falciform ligament is elevated away from optic nerve and cut using arachnoid knife. It allows detaching the medial end of distal dural ligament. Then this cut is extended laterally above the ICA leaving a cuff of dura over it. Exposing the carotid axilla between the $\mathrm{C} 2$ andC 3 is a sign of complete distal dural ring release (Figure 6).
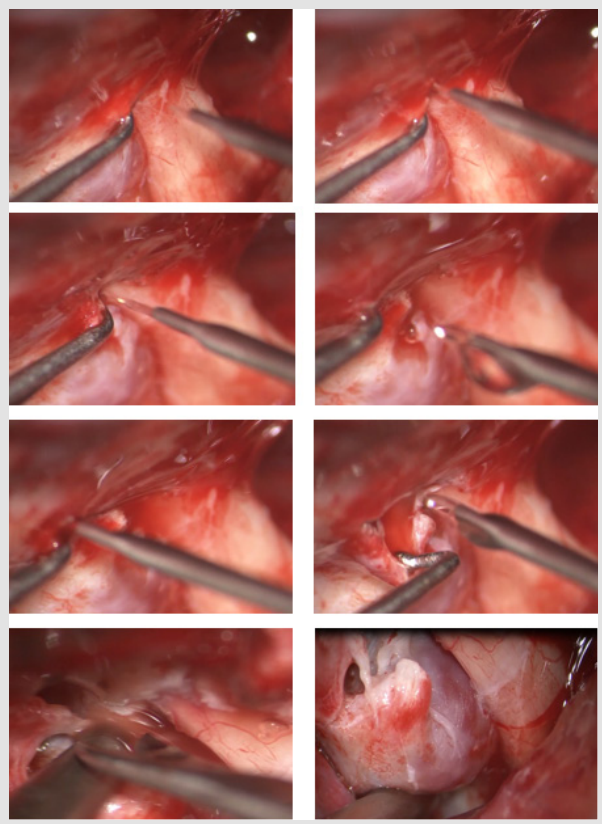

Figure 6: The steps of cutting the distal dural ring using the diamond knife and blunt hook in a case of paraclinoid artery aneurysm. Firstly, the optic sheath is elevated using the blunt hook then is cut by knife. Extension of the cut laterally towards the carotid. Note the remanents of dural ring on the aneurysm dome and the space created between optic nerve and the aneurysm. 


\section{Step 6: Proximal Dural Ring Release}

The lower dural ring is in fact the Carotid-oculomotor membrane (COM) that lines the inferior surface of the ACP. It can be visible through a transcranial routed only by removing the ACP. Medially the COM blends with the dura that lines the carotid sulcus. This ring is often incomplete on the medial side and often a venous channel can follow the paraclinoidal ICA to the upper dural ring. Incising the dura below the ACP release the proximal dural attachment to the ICA, however, this is may be necessary only in cases of carotid cave aneurysms. The surgeon may encounter sinus bleeding, but this can be easily controlled by compression with hemostatic agents. Bipolar coagulation should be avoided not to injure the cranial nerves inside the cavernous sinus (Figure 7).
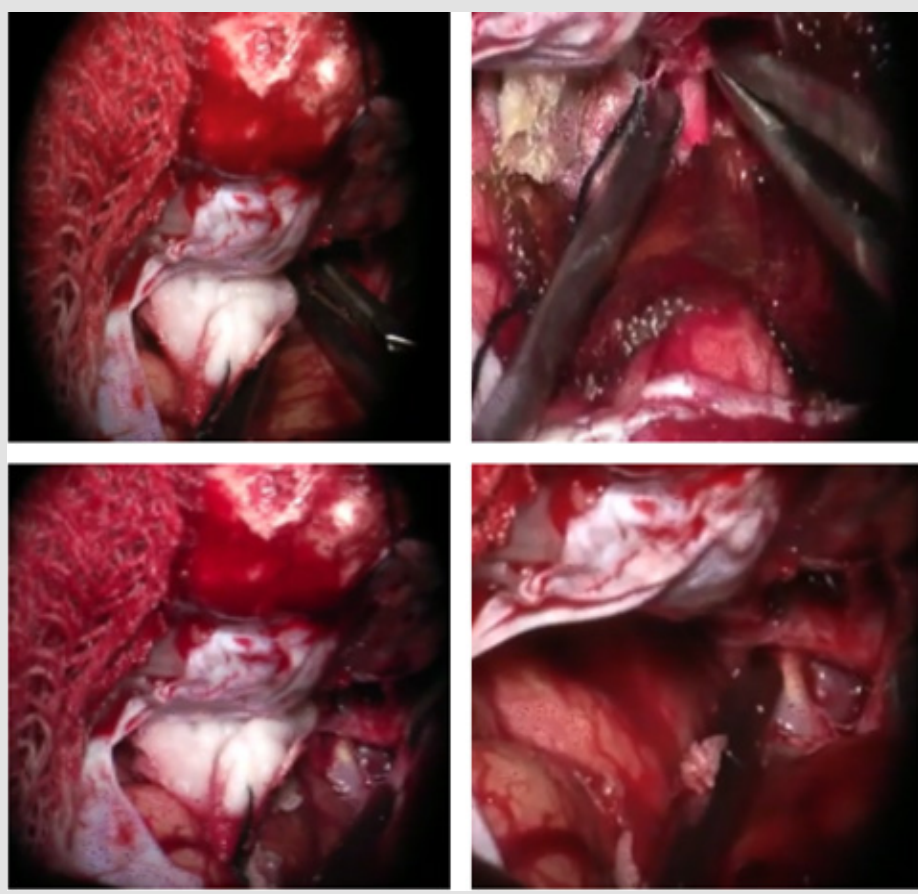

Figure 7: Method of proximal dural ring release (which is opening of roof of cavernous sinus to show intra cavernous sinus aneurysm) opening is done using blunt and sharp technique (upper images) and intra cavernous aneurysm in the lower images.

\section{Discussion}

The most common technique adopted to increase the working area in carotid oculomotor triangle and optic carotid triangle is anterior clinoidectomy [3,7-10]. Anterior clinoidectomy gives a twofold increase in exposure of the optic nerve length and the Oculomotor Carotid Triangle, as well as a three to four fold increase in the maximum width. This substantially improves the surgical exposure of the suprasellar and periclinoid regions [3], however, the ICA is still fixed at the dural ring even after cutting the falciform ligament. Because the mobility of the ICA is restricted, surgery through both spaces will be demanding especially for basilar tip and paraclinoidal aneurysms. These findings agree with Matsuyama's observations on basilar tip aneurysms [3]. The present technique facilitates risk-free mobilization of ICA, which can be dislocated as necessary without undue traction, as it is obligatory if both rings are not fully released. The present paper, in our opinion, is a further contribution to the proper clarification of the complex anatomy of this region and adds useful information for surgeons dealing with demanding pathological processes of the antero-lateral skull base.

\section{References}

1. Gibo H, Lenkey C, Rhoton AL (1981) Microsurgical anatomy of the supraclinoid portion of the internal carotid artery. Journal of neurosurgery 55(4): 560-574.

2. Matsuyama T, Shimomura T, Okumura Y, Sakaki T (1997) Mobilization of the internal carotid artery for basilar artery aneurysm surgery. Journal of neurosurgery 86(2): 294-296.

3. Evans JJ, Hwang YS, Lee JH (2000) Pre-versus post-anterior clinoidectomy measurements of the optic nerve, internal carotid artery, and opticocarotid triangle: a cadaveric morphometric study. Neurosurgery 46(4): 1018-1023.

4. Youssef AS, Abdel Aziz KM, Kim EY, Keller JT, Zuccarello M, et al. (2004) The carotid-oculomotor window in exposure of upper basilar artery aneurysms: a cadaveric morphometric study. Neurosurgery 54(5): 1181-1189.

5. Kim YD, Elhadi AM, Mendes GA, Maramreddy N, Agrawal A, et al. (2015) Quantitative study of the opticocarotid and carotid-oculomotor windows for the interpeduncular fossa, before and after internal carotid artery mobilization and posterior communicating division. Operative Neurosurgery 11(1): 162-180.

6. Seoane E, Rhoton AL, De Oliveira E (1998) Microsurgical anatomy of the dural collar (carotid collar) and rings around the clinoid segment of the internal carotid artery. Neurosurgery 42(4): 869-884. 
7. Noguchi A, Balasingam V, Shiokawa Y, Mc Menomey SO, Delashaw JB (2005) Extradural anterior clinoidectomy. Journal of neurosurgery 102(5): 945-950

8. Froelich SC, Abdel Aziz KM, Levine NB, Theodosopoulos PV, Van Loveren HR, et al. (2007) Refinement of the extradural anterior clinoidectomy surgical anatomy of the orbitotemporal periosteal fold. Operative Neurosurgery 61(5 Suppl 2): 179-186.

ISSN: 2574-1241

DOI: $10.26717 /$ BJSTR.2020.31.005148

Edmundo Valencia Bayona. Biomed J Sci \& Tech Res

(C) This work is licensed under Creative Commons Attribution 4.0 License

Submission Link: https://biomedres.us/submit-manuscript.php
9. Yonekawa Y, Ogata N, Imhof HG, Olivecrona M, Strommer K, et al. (1997) Selective extradural anterior clinoidectomy for supra- and parasellar processes. Journal of neurosurgery 87(4): 636-642.

10. Dolenc VV (1985) A combined epi- and subdural direct approach to carotid-ophthalmic artery aneurysms. Journal of neurosurgery 62(5): 667-672.

$\begin{array}{ll}\text { BIOMEDICAL } & \text { Assets of Publishing with us } \\ \text { RESEARCHES } & \text { - Global archiving of articles } \\ \text { - Immediate, unrestricted online access } \\ \text { - Rigorous Peer Review Process } \\ \text { - Anttps://biomedres.us/ }\end{array}$

